\title{
Erratum to: Online Intermediaries for Co-Creation
}

\section{Erratum to: \\ C.W. Künne, Online Intermediaries for Co-Creation, Progress in IS, DOI 10.1007/978-3-319-51124-5}

In the original version of the book, Annexures have to be removed from book back matter and have to be treated as Chapter 7. The erratum book has been updated with the change.

The updated online version of this book can be found at

http://dx.doi.org/10.1007/978-3-319-51124-5 